\title{
Correlation between Anti-Corrosion Performance and Optical Reflectance of Nano Fluoride Film on Biodegradable Mg-Zn-Zr Alloy: a Non-Destructive Evaluation Approach
}

\author{
Da-Jun Lin ${ }^{1}$, Fei-Yi Hung ${ }^{1, *}$, Ming-Long Yeh ${ }^{2}$, Hung-Pang Lee ${ }^{2}$,Truan-Sheng Lui ${ }^{1}$ \\ ${ }^{1}$ Department of Materials Science and Engineering, National Cheng Kung University, Tainan 701, \\ TAIWAN. \\ ${ }^{2}$ Department of Biomedical Engineering, National Cheng Kung University, Tainan 701, TAIWAN. \\ *E-mail: fyhung@mail.ncku.edu.tw
}

doi: $10.20964 / 2017.05 .24$

Received: 11 February 2017 / Accepted: 5 March 2017 / Published: 12 April 2017

\begin{abstract}
Magnesium alloy is promising new biomaterial due to its satisfactory mechanical performance, biocompatibility and degradation of non-toxic substances. However, the dual problems of corrosion and hydrogen evolution require overcoming in order to reach a practical application level. For anticorrosion modification, fluoride conversion treatment was chosen to provide varied $\mathrm{MgF}_{2}$ coatings on the microstructure-modified $\mathrm{Mg}-\mathrm{Zn}-\mathrm{Zr}$ alloy The aim of the present study was to investigate the influence of coating structures and their corresponding corrosion resistance. The fluoride coatings were constructed with nano-crystalline composites, which demonstrated that $\mathrm{Mg}-\mathrm{Zn}$ precipitates participate in the coating-growth mechanism. In addition, the improved corrosion resistance was also systematically investigated. Compared with the pristine substrate, the F24h and F48h specimens significantly improved the anti-corrosion performance. Moreover, this report is the first report to propose a non-destructive evaluation method through simultaneous evaluation of the corrosion behavior and the establishment of a correspondence surface reflectance for fluoride conversion coatings on $\mathrm{Mg}-\mathrm{Zn}-\mathrm{Zr}$ alloy.
\end{abstract}

Keywords: Magnesium alloy, fluoride conversion coating, anti-corrosion, optical reflectance

\section{$\underline{\text { FULL TEXT }}$}

(C) 2017 The Authors. Published by ESG (www.electrochemsci.org). This article is an open access article distributed under the terms and conditions of the Creative Commons Attribution license (http://creativecommons.org/licenses/by/4.0/). 